\title{
Prediction of the Stamped Part Thinning Depending on Its Geometry and Blank Material
}

Jan Řiháček, Kamil Podaný, František Faltýnek

Institute of Manufacturing Technology, Faculty of Mechanical Engineering, Brno University of Technology. Technická 2896/2, 61669 Brno. Czech Republic.E-mail: rihacek.j@fme.vutbr.cz, podany@fme.vutbr.cz, 152489@vutbr.cz

The paper deals with a design of new dimple geometry with a view to minimizing its thinning. In this case, three types of blank materials were analyzed, i.e. ferritic steel $\mathrm{X2CrCuTi18}$, austenitic steel X5CrNi18-10 and austenitic steel X5CrNi18-10 with additional heat treatment. Thinning analysis for different dimple geometry and blank material is performed with a numerical simulation using finite element method in ANSYS software. To verify the accuracy of the numerical simulation, a practical stamping of the part with initial design and comparison between resulting thinning values, which is determined by ANSYS software and experimental microscopic measurement, is also performed.

Keywords: Numerical Simulation, Forming, Dimple, ANSYS, Finite Element Method

\section{Introduction}

In the most cases, the creation of shallow dimples in a sheet metal part is intended to increase its stiffness. In general, it is an unsymmetrical bending to a non-expandable shape, most often in the shape of grooves, wherein the dimples may be of substantially any shape. [1], [2] The article is aimed at optimization of the circular dimples geometry on the stamped part (Fig. 1) in the application for the automotive industry. Production of the optimized component is carried out at Hanon Systems Autopal company, which belongs to the Hanon Systems concern. The company is in the automotive industry focusing on systems that regulate both the temperature inside the car cabin and the engine temperature.

With regard to the confidentiality, only approximate dimensions of the optimized part are given. Mentioned dimples here primarily do not increase the stiffness of the whole part, but they serve primarily as a spacer to which another part is soldered, see the detail of the soldered joint in Fig. 2. When a thermal load is applied on this assembly, during operating load, cracks occur in areas with the most thinning. Therefore, the main aim is to optimize the dimples shape with the simultaneous analysis of the blank material to obtain the smallest dimple thinning in transitions between the dimple and a flat region of the stamped part. [3]

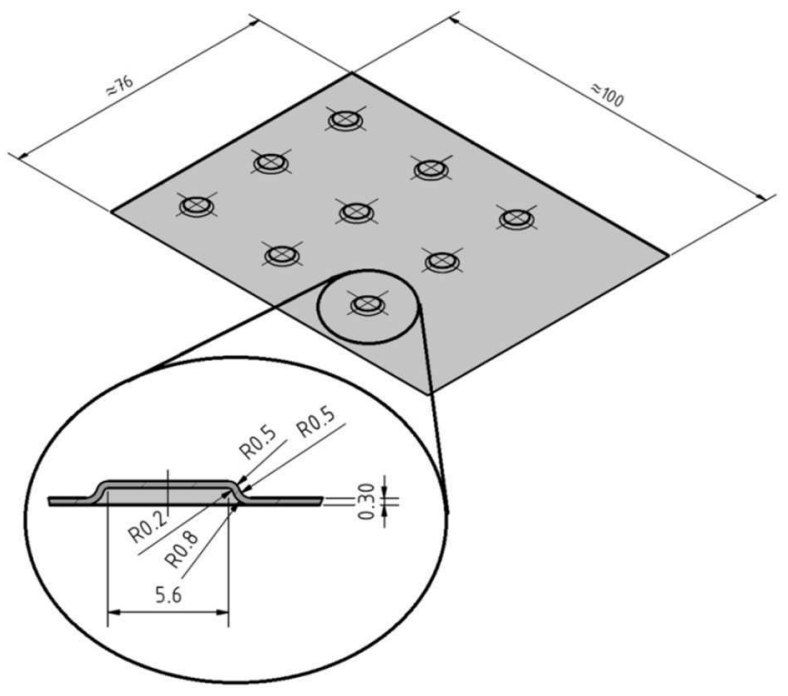

Fig. 1 Basic Dimensions of the Optimized Part

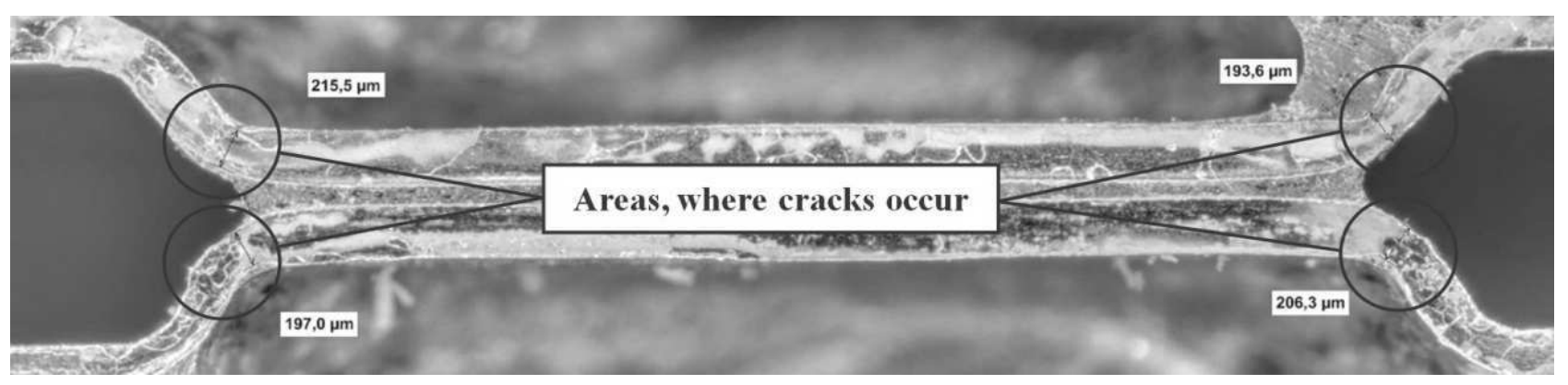

Fig. 2 Crosssection of Two Soldered Dimples [3]

The current initial blank for the production of the mentioned part is a $0.3 \mathrm{~mm}$ thick sheet, which is made of $\mathrm{X} 2 \mathrm{CrCuTi1} 8$ steel. It is stainless ferritic steel with chemi- cal composition, which is shown in Tab. 1. Basic mechanical and physical properties, which are for $20^{\circ} \mathrm{C}$ defined by the standard, are also mentioned in Tab. 2 .

Tab. 1 Chemical Composition of X2CrCuTi18 Steel [3]

\begin{tabular}{cccccccccc} 
& $\mathrm{C}$ & $\mathrm{Mn}$ & $\mathrm{P}$ & $\mathrm{S}$ & $\mathrm{Si}$ & $\mathrm{Cr}$ & $\mathrm{Cu}$ & $\mathrm{Ti}$ & $\mathrm{N}$ \\
\hline $\min$ & - & - & - & - & - & 16.000 & 0.300 & - & - \\
\hline $\max$ & 0.025 & 1.000 & 0.040 & 0.030 & 1.000 & 20.000 & 0.800 & 0.800 & 0.250 \\
\hline
\end{tabular}


Tab. 2 Basic Mechanical and Physical Properties of X2CrCuTi18 Steel [3]

\begin{tabular}{cccccc}
\hline Yield Stress & Ultimate Strength & Ductility & Young's modulus & Poisson's Ratio & Density \\
\hline $\mathrm{R}_{\mathrm{p} 0.2}[\mathrm{MPa}]$ & $\mathrm{R}_{\mathrm{m}}[\mathrm{MPa}]$ & $\mathrm{A}_{80}[\%]$ & $\mathrm{E}[\mathrm{GPa}]$ & $\mu[-]$ & $\rho\left[\mathrm{kg} \cdot \mathrm{m}^{-3}\right]$ \\
\hline 205 & 390 & 22 & 195 & 0.31 & 7700 \\
\hline
\end{tabular}

Another considered material variant is a sheet of the same thickness of $\mathrm{X} 5 \mathrm{CrNi18}-10$ steel, which, due to $10 \%$ nickel presence, ranks among austenitic stainless steels. [4] The contents of all alloying elements are shown in
Tab. 3. Compared to the previous material, mechanical properties are characterized by low yield strength and high ductility, see Tab. 4.

Tab. 3 Chemical Composition of X5CrNi18-10 Steel [6]

\begin{tabular}{ccccccccc} 
& $\mathrm{C}$ & $\mathrm{Mn}$ & $\mathrm{P}$ & $\mathrm{S}$ & $\mathrm{Si}$ & $\mathrm{Ni}$ & $\mathrm{Cr}$ & $\mathrm{N}$ \\
\hline $\min$ & - & - & - & - & - & 8.000 & 17.000 & - \\
\hline $\max$ & 0.070 & 2.000 & 0.045 & 0.030 & 1.000 & 10.500 & 20.000 & 0.100 \\
\hline
\end{tabular}

Tab. 4 Basic Mechanical and Physical Properties of X5CrNi18-10 Steel [6]

\begin{tabular}{cccccc}
\hline Yield Stress & Ultimate Strength & Ductility & Young's modulus & Poisson's Ratio & Density \\
\hline $\mathrm{R}_{\mathrm{p} 0.2}[\mathrm{MPa}]$ & $\mathrm{R}_{\mathrm{m}}[\mathrm{MPa}]$ & $\mathrm{A}_{80}[\%]$ & $\mathrm{E}[\mathrm{GPa}]$ & $\mu[-]$ & $\rho\left[\mathrm{kg} \cdot \mathrm{m}^{-3}\right]$ \\
\hline 190 & $500 \div 750$ & 37 & 199 & 0.3 & 8030 \\
\hline
\end{tabular}

As a standard for this type of steel, dissolving annealing is carried out in which austenite is homogenized followed by rapid cooling. This procedure prevents local decrease of the chromium concentration and loss of resistance to intergranular corrosion. [4], [5] Moreover, additional heat treatment - annealing can be carried out, that further improves the steel structure and its properties. The temperature of $1040{ }^{\circ} \mathrm{C}$ is reached by the initial heating. After 3 minutes at constant temperature, the step heating is continued at $1060{ }^{\circ} \mathrm{C}, 1070{ }^{\circ} \mathrm{C}$ and $1080^{\circ} \mathrm{C}$, always with the same delay. The heating process is followed by free air cooling to ambient temperature. It is important to note, that for the production of the desired part, X5CrNi18-10 steel was available both after standard annealing and after additional annealing.

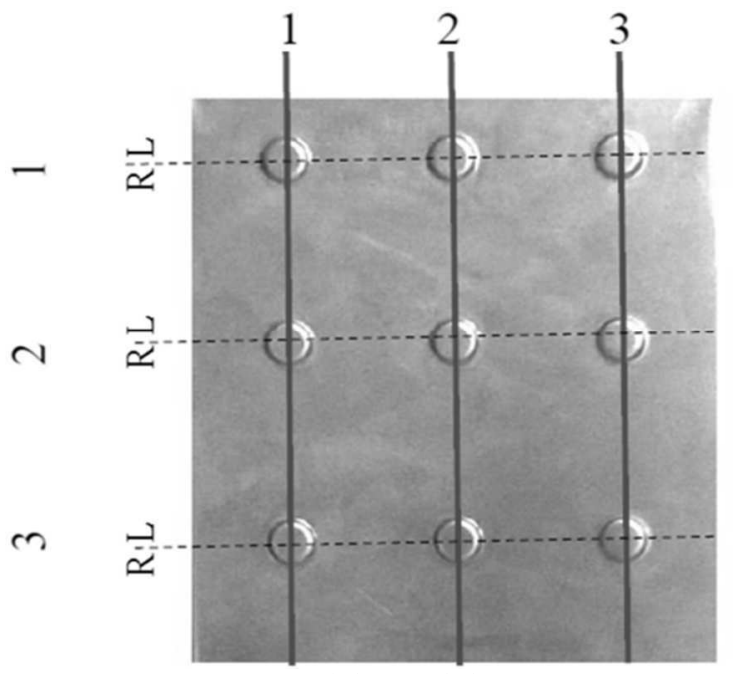

a) logitudal cuts

\section{Analysis of the Current State}

Firstly, it is necessary to measure the thinning of the critical areas on actual stamped parts with dimples. This means to measure thinning of parts that were made of $\mathrm{X} 2 \mathrm{CrCuTi} 18$ steel. The SSM-3E microscope, which is equipped with a USB camera, was used to perform wall thickness measurements on manufactured parts with support of Dino-Capture 2.0 software. Overall, two stamped parts were cut into longitudinal and transverse sections taken through the dimples, as it is schematically shown in Fig. 3. The red solid line means a cut in the part, the dashed black line separates the left and right sides of dimples.

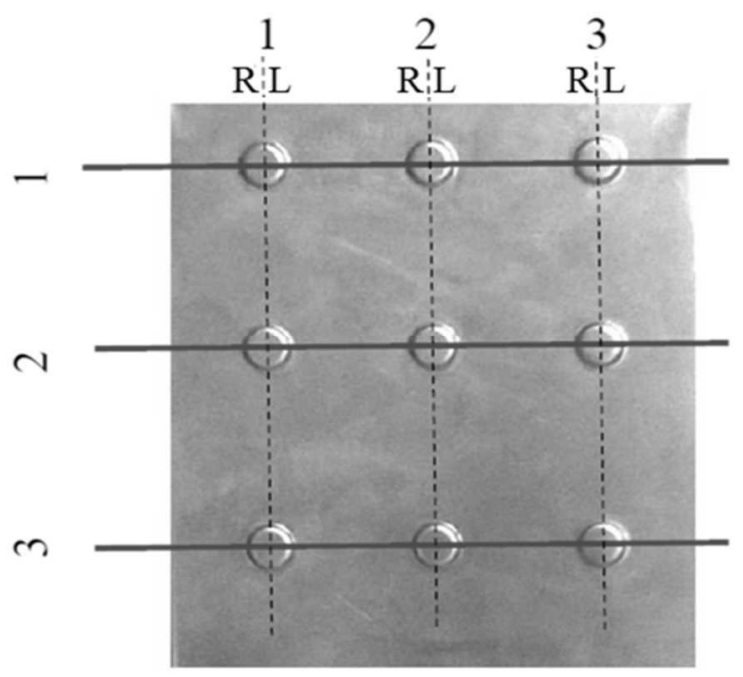

b) transversal cuts

Fig. 3 Cutting Sections on Stamped Parts

In each cut, for the given dimple, the place with the greatest thinning was found by the microscopic measurement, see an example of the thinning evaluation in Fig. 4. The largest thinning was found at the fillet location at the bottom of each dimple.

From the measured data, the average values were calculated for individual rows and columns. Left and right sides of each cut dimple were also distinguished in order to observe the effect of the punch and the die displacement. In both longitudinal and transverse cuts, the right and left side thinning values differ in approx. $0.009 \mathrm{~mm}$. Therefore, the utilization of a perfectly coaxial tool could mean a maximum increase in thickness by $3 \%$ in relation to the initial thickness of the blank $\mathrm{s}=0.3 \mathrm{~mm}$. 


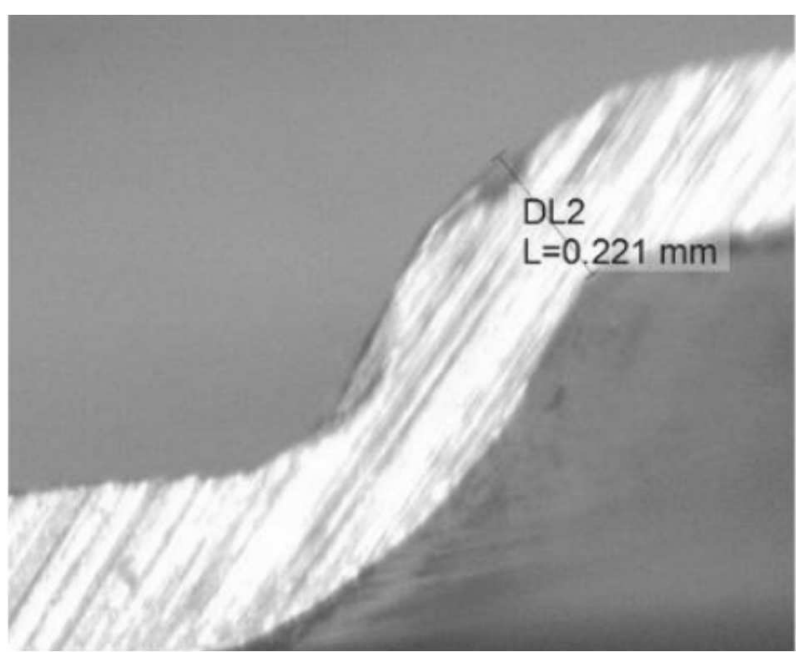

a) left side of the dimple

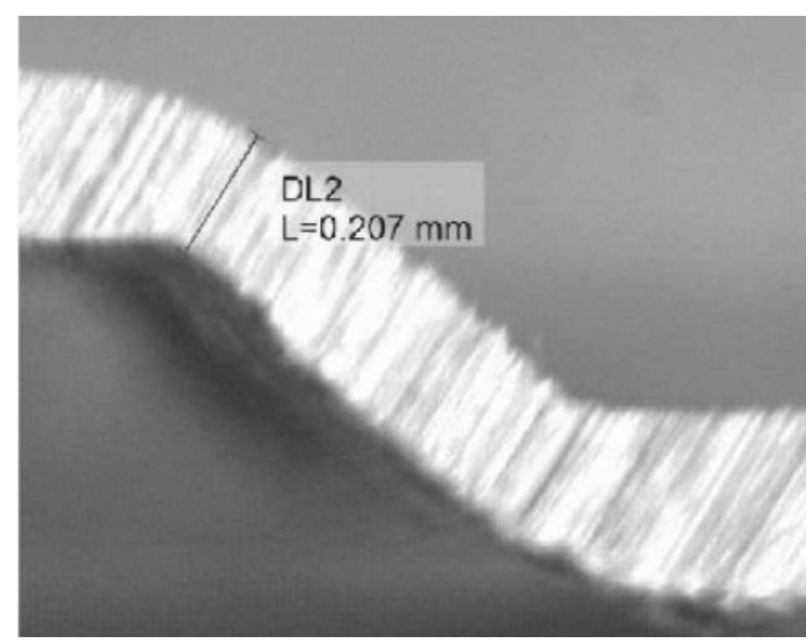

b) right side of the dimple

Fig. 4 Example of Measured Dimple

Tab. 5 Thickness Values for Longitudal Cuts in $\mathrm{mm}$

\begin{tabular}{l|l|c|c|c|c}
\hline \multicolumn{2}{l|}{} & Column 1 & Column 2 & Column 3 & Mean value \\
\hline \multirow{2}{*}{ Row 1} & Right side & 0.178 & 0.174 & 0.177 & 0.176 \\
& Left side & 0.202 & 0.193 & 0.201 & 0.199 \\
\multirow{2}{*}{ Row 2} & Right side & 0.156 & 0.192 & 0.199 & 0.182 \\
& Left side & 0.189 & 0.188 & 0.202 & 0.193 \\
\multirow{2}{*}{ Row 3} & Right side & 0.196 & 0.192 & 0.205 & 0.198 \\
& Left side & 0.212 & 0.202 & 0.200 & 0.205 \\
\hline \multicolumn{2}{c}{ Summary mean value } & Right sides & & 0.185 \\
\multicolumn{2}{l}{} & Left sides & & 0.199 \\
\end{tabular}

Tab. 6 Thickness Values for Transversal Cuts in $\mathrm{mm}$

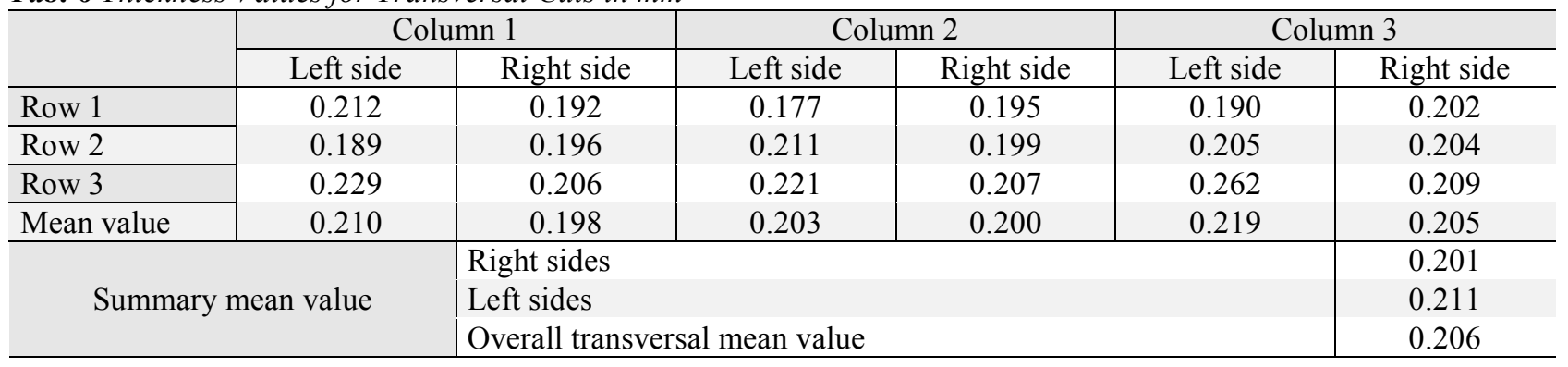

\section{Geometry Optimization by Using Numerical Simulation}

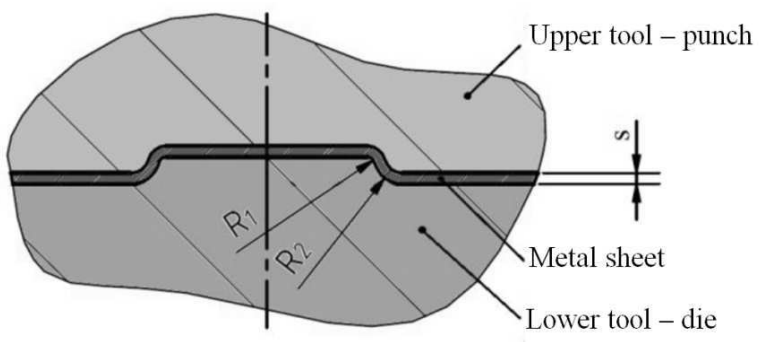

Fig. 3 Geometry of Stamped Dimple [3]

The aim of the optimization is to choose from various forming tools shapes combinations such that the thinning of the stamped dimples wall at the radii of $R_{1}$ and $R_{2}$ is as small as possible (Fig. 3). The dimple must still simultaneously have an acceptable shape due to its function of the spacer element. In the initial condition, the dimple geometry consists of fillet radii of $\mathrm{R}_{1}=0.2 \mathrm{~mm}, \mathrm{R}_{2}=0.8$ $\mathrm{mm}$ and initial sheet thickness $\mathrm{s}=0.3 \mathrm{~mm}$. In addition, the thinning will be evaluated for three different materials, X2CrCuTi18 ferritic steel, X5CrNi18-10 austenitic steel and $\mathrm{X} 5 \mathrm{CrNi18-10}$ austenitic steel with additional heat treatment.

The dimple geometry is determined primarily by the size of the radii $\mathrm{R}_{1}$ and $\mathrm{R}_{2}$. If the size of these radii changes, the strain and stress will change during the stamping process, as well as the final thickness of the dimple wall. For this purpose, a numerical simulation with the support of the finite element method, that can serve to analyze a wide range of forming analyzes [7], [8], [9], appears to be a highly effective tool. In this case, the choice of the ideal $\mathrm{R}_{1}$ and $\mathrm{R}_{2}$ combination, depending on the size of the thinning (or the principal strain), was performed by using an optimization tool in the ANSYS Workbench software. Since the ANSYS software does not allow a thickness 
change evaluation, the thinning value has to be determined by recalculating the the principal strain over the thickness using equation (1).

Where:

$$
\mathbf{s}=\mathbf{s}_{\mathbf{0}} \cdot \mathbf{e}^{\varphi_{3}}[\mathrm{~mm}]
$$

s...Actual thickness [mm],

$\mathrm{s}_{0} \ldots$ Initial thickness $(0.3 \mathrm{~mm})[\mathrm{mm}]$,

$\varphi_{3} \ldots$ True principal strain over the thickness [-].

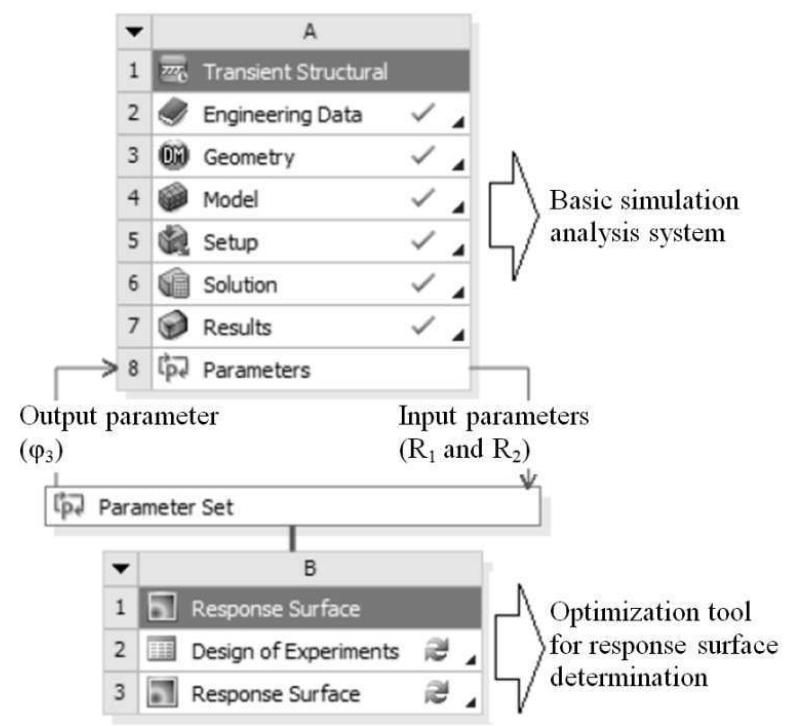

Fig. 4 Basic Schema of the Project in ANSYS Workbench Software [3]

The mentioned tool uses the response surface method, which searches for the corresponding output variables according to several input parameters. [10] Based on their interdependence, an optimal combination of input parameters is then sought. Fig. 4 shows a solution schema in ANSYS Workbench. Due to the parameterization of the whole model, the geometry change, based on input parameters, could be controlled by a program that calculated a minimal strain value $\varphi_{3}$ for each combination and thus a minimal dimple thickness.

\subsection{Geometric model}

The geometry description is based on the CAD data, which were provided by Hanon Systems. For the sheet forming simulations using FEM, it is preferable to use shell elements for discretization, that was also used in this case. The geometric model for the detail of one dimple after discretization is shown in Fig. 5. The stamping tools were considered as ideal rigid.

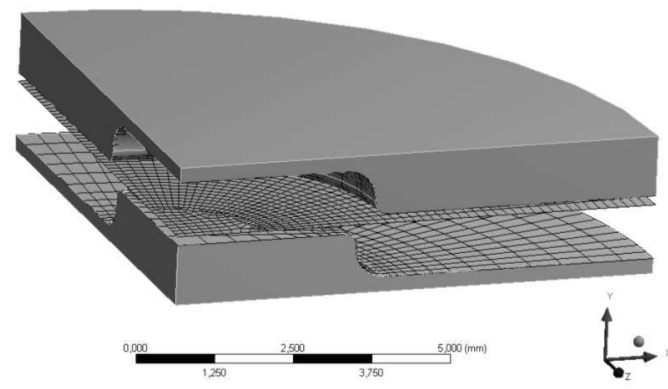

Fig. 5 Discretization in FEM Model [3]

\subsection{Material model}

For above-mentioned three materials, tensile tests were performed in the rolling direction. Thus obtained engineering stress-strain curves (hardening curves) were subsequently converted into true values. A comparison of the detected curves after recalculation (from the yield stress to the ultimate strength of each material) to true stress-strain values is given in Graph 1. Together with elastic properties (Tab. 2 and Tab. 4) and other simulation parameters (i. e. friction coefficient, which was determined as $\mu=0,12)$, recalculated true values can be used as a material model for FEM simulations. Moreover, normal anisotropy coefficients were also identified for the anisotropic behavior of the materials, see Tab. 5 .

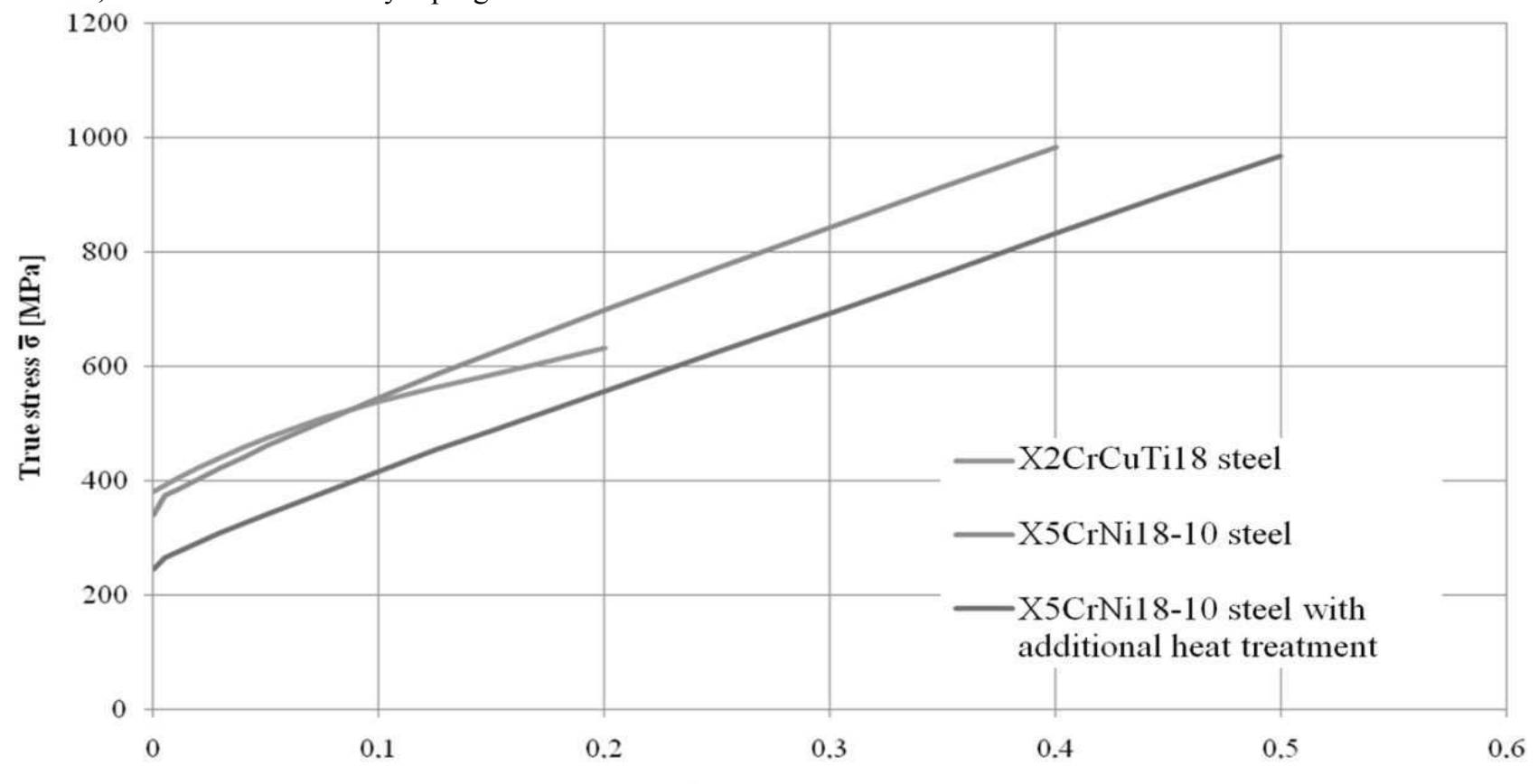

True plastic strain $\varphi[-]$

Graph 1 True Stress-Strain Curves of Solved Materials 
Tab. 5 Normal Anisotropy Coefficients of Solved Materials

\begin{tabular}{c|ccc}
\hline & X2CrCuTi18 steel & X5CrNi18-10 steel & X5CrNi18-10 steel with additional annealing \\
\hline $\mathrm{r}_{0^{\circ}}$ & 1.291 & 0.865 & 0.902 \\
\hline $\mathrm{r}_{45^{\circ}}$ & 0.831 & 1.174 & 1.087 \\
\hline $\mathrm{r}_{90^{\circ}}$ & 1.198 & 0.972 & 0.815 \\
\hline \hline $\mathrm{r}_{\mathrm{s}}$ & 1.038 & 1.046 & 0.973 \\
\hline
\end{tabular}

\subsection{Simulation Results}

Due to its strength characteristics, ferritic stainless steel $\mathrm{X} 2 \mathrm{CrCuTi} 18$ shows the worst values of thinning in

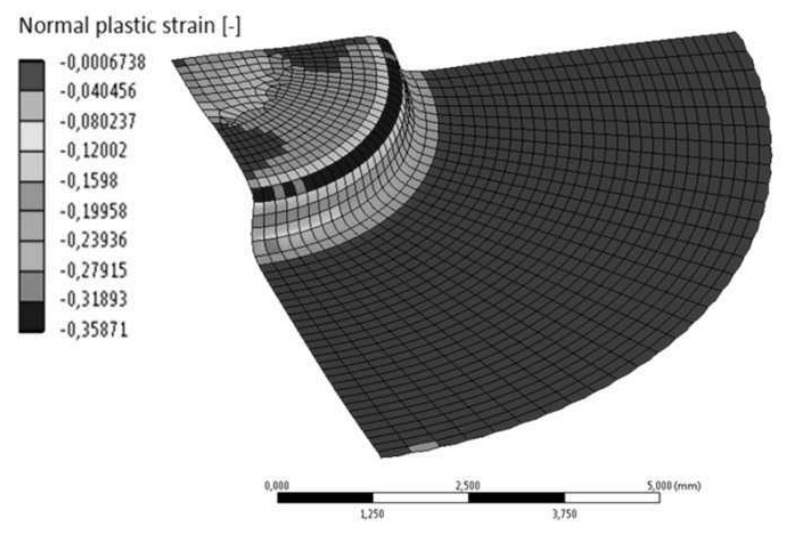

a) Detail for One Dimple comparison with austenitic sheets, as expected. A sample of the third principal strain distribution (over the thickness) in the direction of the sheet thickness after the stamping process is shown in Fig. 6.

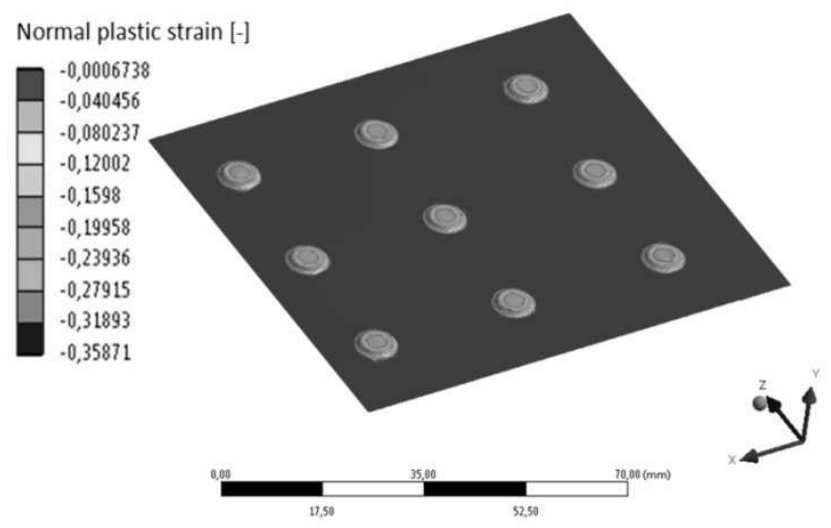

b) Overall View of the Stamped Part

Fig. 6 Third Principal Strain Distrimution After Stamping

This is the result for the combination of $\mathrm{R} 1=0.2 \mathrm{~mm}$ and $\mathrm{R} 2=0.5 \mathrm{~mm}$, i. e. current state. After the recalculation according equation (1), the lowest strain corresponds to a thickness of $0.222 \mathrm{~mm}$ (25.9\% thinning). The response surface for the other $R_{1}$ and $R_{2}$ values is shown in Graph 2. As it is logically evident from the mentioned diagram, the wall thinning is decreasing along with the increasing radii $R_{1}$ and $R_{2}$.

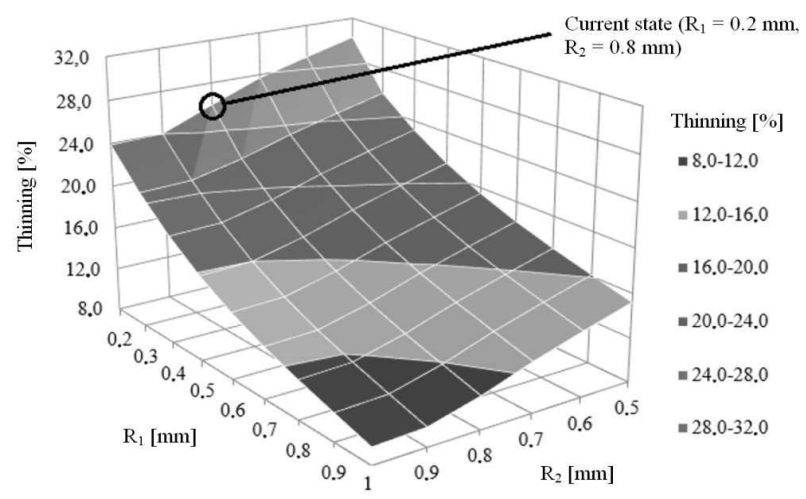

Graph 2 Dependency of Wall Thinning on $R_{1}$ and $R_{2}$ for X2CrCuTi18 Steel

For verification of the accuracy of numerical simulation results, it is also necessary to compare the FEM simulation of the current state with the above-mentioned experimental thickness measurement. By simulating the current state, a minimum thickness of $0.222 \mathrm{~mm}$ was found at a critical point (near $\mathrm{R}_{1}$ radius), corresponding to the thinning value of $25.9 \%$. By microscopical measuring, $33.3 \%$ thinning was found as the largest value, i. e. difference of $7.4 \%$. It is important to note, that the difference can be affected by many factors, such as changes in friction coefficient, but namely by relative displacement of stamping tools toward each other in practical manufacturing process etc. In view of the foregoing, the model can be regarded as sufficient to search the optimal geometry parameters, a radius $\mathrm{R}_{1}$ and $\mathrm{R}_{2}$. Austenitic stainless steel X5CrNi18-10 without additional heat treatment confirmed the expected reduction in thinning values. As in the previous case, the dependence of thinning on input simulation parameters $\left(R_{1}\right.$ and $\left.R_{2}\right)$ can be observed in Graph 3. Unlike steel, it is possible to achieve a smaller thinning. For the current state, minimal thining value of $23.8 \%$ was found.

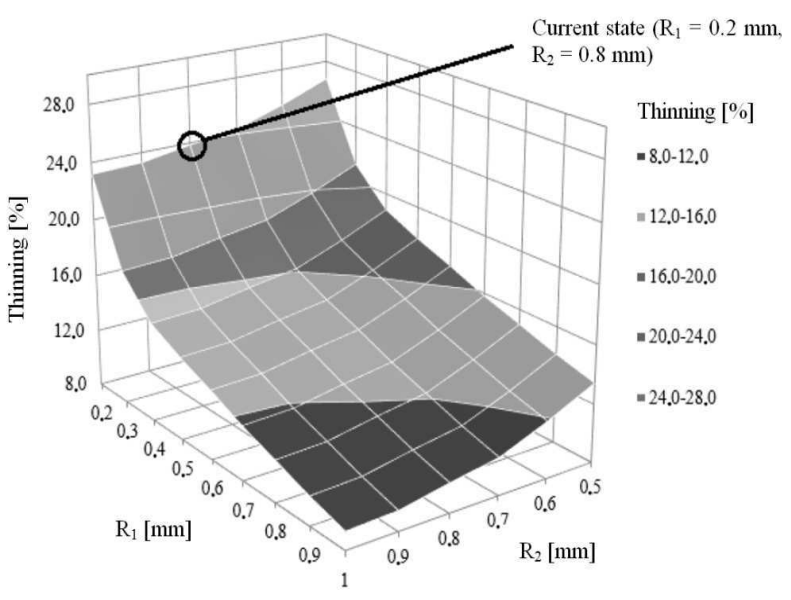

Graph 3 Dependency of Wall Thinning on $R_{1}$ and $R_{2}$ for X5CrNi18-10 Steel 


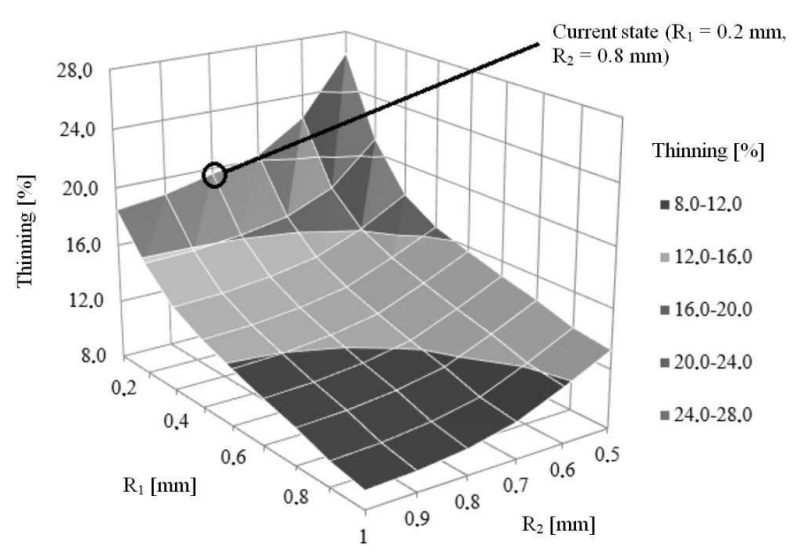

Graph 4 Dependency of Wall Thinning on $R_{1}$ and $R_{2}$ for X5CrNi18-10 Steel with Additional Heat Treatment

The third and final material variant is austenitic stainless steel $\mathrm{X} 5 \mathrm{CrNi} 18-10$ with additional heat treatment. By changing of the main geometric parameters $\left(\mathrm{R}_{1}\right.$ and $\mathrm{R}_{2}$ ), a graph of the dependence between percentage thinning of the material, $R_{1}$ radius and $R_{2}$ radius was also for this third case constructed, see Graph 4. For the

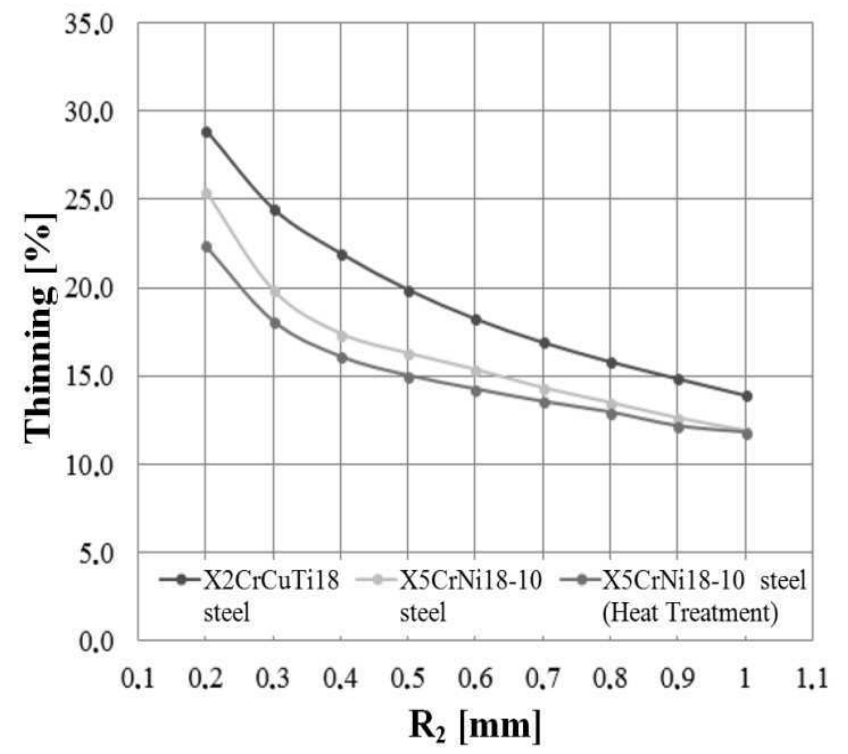

a) for $R_{2}=0,6 \mathrm{~mm}$ current state, the lowest thinning value was found as $19.6 \%$, which is the best result for all three cases. As in the two previous cases, it is also possible to state, that the radius $R_{1}$ has more impact on thinning values, compared to $\mathrm{R}_{2}$ influence.

\section{Results and Discussion}

As it follows from the above-mentioned, X5CrNi1810 steel with additional heat treatment seems to be the most advantageous. The graphs presented above show the thinning depending on the dimple geometry. However, attention should also be paid to the materials influence across these graphs. The comparison of thinning values shows that the greatest influence of the material properties appears for the small radii $R_{2}$ and namely $R_{1}$. By increasing of these parameters the material's influence is reduced. This is illustrated in Graph 5a, where the thinning curves for all three materials can be seen, depending on $\mathrm{R}_{1}$ at $\mathrm{R}_{2}=0.6 \mathrm{~mm}$. Furthermore, Graph $5 \mathrm{~b}$ shows another case, i. e. the same dependence for $R_{2}=1 \mathrm{~mm}$. Curves characterizing the thinning are approaching with increasing values of radii $R_{1}$ and $R_{2}$.

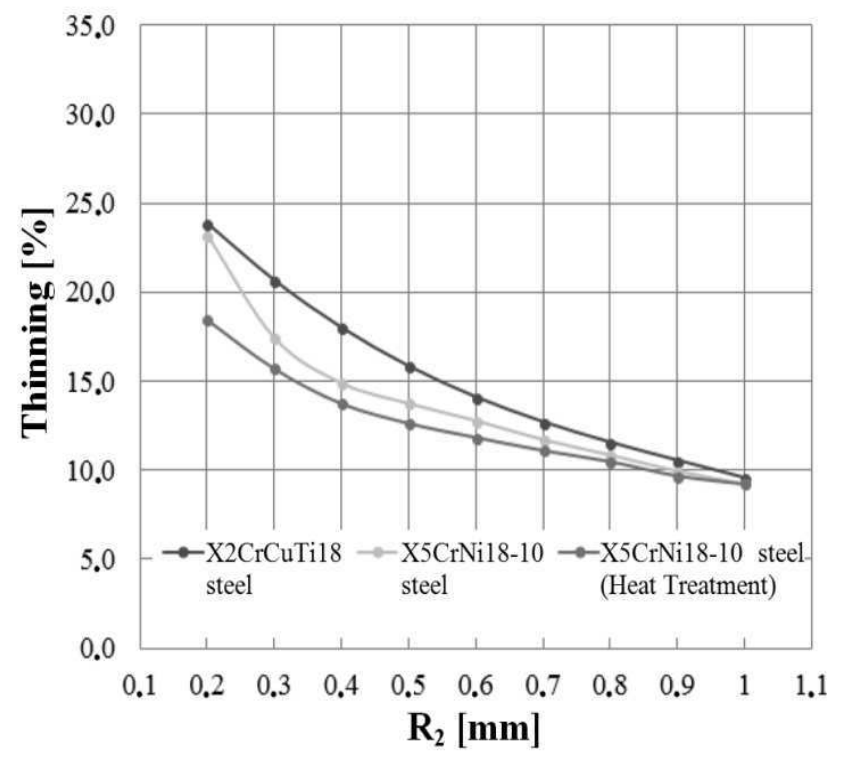

b) for $R_{2}=1 \mathrm{~mm}$

Graph 5 Effect of Material and $R_{l}$ Radius on Thinning

There are several paths to reach the lower wall thinning. The first way is to increase both radii to values as close as possible to the maximum in a tested range. In this case, it is not important what type of considered materials will be used, because for $\mathrm{R}_{1}=\mathrm{R}_{2}=1.0 \mathrm{~mm}$, the difference in the thinning is in the order of tenths of a percent. Therefore, it makes no sense to use a more expensive material option. In other hands, the dimple function as a spacer element defining the position of the entire part with respect to the whole assembly may be in conflict with its shape change. For this reason, if it is not possible to change the geometry to the recommended one, the second way how to increase the dimple wall thickness is just changing of the blank material.

\section{Conclusions}

The article was focused on the design of the dimple geometry depending on its thinning. In this case, the determination of material thinning during the stamping operation was performed by using numerical analysis, i.e. finite element method. Overall, three types of blank materials were analyzed (ferritic steel, austenitic steel and austenitic steel with additional heat treatment) with initial thickness of $0.3 \mathrm{~mm}$. Before the mentioned analysis, mechanical behavior of all analyzed materials was evaluated by performing the tensile test. In the following, experimental evaluation of thinning was done by using microscopic measurement on the current geometry. 
The theoretical analysis showed that the current state (ferritic steel, $\mathrm{R}_{1}=0.2 \mathrm{~mm}, \mathrm{R}_{2}=0.8 \mathrm{~mm}$ ) cannot be stamped with less thinning than approx. $26 \%$, varying from the minimal experimentally determined value by $7.4 \%$. If the tool geometry is changed to $R_{1}=1 \mathrm{~mm}, R_{2}=1 \mathrm{~mm}$, the thinning value reaches the lower value of $9.55 \%$. When austenitic steel is using, it is possible to achieve even lower values for the same geometry, namely $9.24 \%$. But austenitic steel with additional heat treatment (annealing) achieves the best thinning values (thinning of 9.23 $\%$ for $\mathrm{R}_{1}, \mathrm{R}_{2}=1 \mathrm{~mm}$ ). It is obvious that the use of austenitic steel with additional heat treatment can positively affect the thinning of the material, up to $0.32 \%$. In all cases, it can be observed that the change in rounding value $R_{1}$ brings a steeper course of thinning change, compared to $R_{2}$. Therefore it is obvious that the effect of the radius $R_{1}$ is more pronounced for all investigated cases.

\section{Acknowledgement}

The work was carried out as a part of the cooperation with Hanon Systems Autopal company, which provided the necessary support.

\section{References}

[1] KUMAR, V., QUATTAWI, A. (2018). Nusselt Number and Friction Factor Correlations of Three Sides Concave Dimple Roughened Solar Air Heater. In: Renewable Energy, Vol. 12, No. 2, pp. 355 - 377. Elsevier. United Kingdom.

[2] HOSFORD, W. F., CADDEL, R. M. (2014). Metal forming: Mechanics and metallurgy. Cambridge University Press, United Kingdom.
[3] FALTÝNEK, L. (2018). Geometry Optimization of the Stamped Part. Brno University of Technology. Czech Republic.

[4] PTÁČEK, L. (2002). Nauka o materiálu II. CERM. Brno.

[5] ČSN EN 10088-1. (2015) Stainless Steel - Part 1: Overview of Stainless Steels. pp. 1-80. Czech Standards Institute. Prague.

[6] К̌IHÁČEK, J. (2018). Utilization of Hydroforming Hechnology to Create a Structured Surface of Solar Panel. Brno University of Technology. Czech Republic.

[7] PETERKOVÁ, E. (2016). Biaxial Test of Tubes Using Elastomer. In: Manufacturing technology. Vol. 16, No. 4, pp.765-771. J. E. Purkyne University. Czech Republic.

[8] ŽMINDÁK, M., MEŠKO, J., PELAGIĆ, Z., ZRAK, A. (2014). Finite element analysis of crack growth in pipelines. In: Manufacturing Technology. Vol. 14, No. 1, pp. 116-122. J. E. Purkyne University. Czech Republic..

[9] ALBAT, M., QUATTAWI, A. (2017). Numerical Simulation of Sheet Metal Forming: a Review. In: The International Journal of Advanced Manufacturing Technology, Vol. 89, No. 1, pp. 1235 1250. Springer. United Kingdom.

[10] LEE, H.-H. (2017). Finite Element Simulations with ANSYS Workbench 17: Theory, Applications, Case Studies. SDC Publishing, United States. 